\title{
Diagnostic accuracy of semiquantitative point of care urine albumin to creatinine ratio and urine dipstick analysis in a primary care resource limited setting in South Africa
}

Sean D. Currin ${ }^{1,2^{*}}$ (D) Mwawi S. Gondwe ${ }^{3}$, Nokthula B. Mayindi ${ }^{3}$, Shingirai Chipungu ${ }^{3}$, Bongekile L. Khoza ${ }^{3}$, Stephen Tollman ${ }^{3,4}$, June Fabian ${ }^{3,5+}$, Jaya A. George ${ }^{1,2+}$ and On behalf of the ARK Consortium

\begin{abstract}
Background: The prevalence of chronic kidney disease (CKD) is predicted to rise over the next few decades. In resource-limited settings access to central laboratory services is limited. Point-of-care (POC) urine dipstick testing offers the potential to detect markers of kidney damage (albuminuria) as well as markers of other disease processes. We evaluated the diagnostic accuracy of the semi-quantitative albumin-creatinine ratio (ACR) Sysmex UC-1000 POC urine dipstick system as well as the extent of other abnormal dipstick findings in urine.

Methods: 700 participants from a rural area in South Africa were screened for albuminuria. A spot urine sample was used to measure POC and central laboratory ACR. We determined the sensitivity, specificity, positive predictive value and negative predictive value of the POC ACR, and recorded dipstick parameters.

Results: The prevalence of albuminuria was $11.6 \%$ (95\%Cl; 9.3-14.2). Those with albuminuria had higher mean diastolic ( 82 vs $79 \mathrm{mmHg}, p=0.019$ ) and systolic (133 vs $128 \mathrm{mmHg}, p=0.002$ ) blood pressures and a higher proportion of diabetes mellitus ( 17.6 vs $4.9 \%, p<0.001)$. The sensitivity of the POC ACR system was 0.79 , specificity 0.84 , positive predictive value 0.39 and negative predictive value 0.97 . The sensitivity improved to $0.80,0.85,0.85$ and 0.89 in those with elevated blood pressure, diabetes mellitus, HIV positive status, and those 65 years and older, respectively. Abnormalities other than albuminuria were detected in 240 (34.3\%) of the samples; 88 (12.6\%) were positive for haematuria, 113 (16.1\%) for leucocytes, 66 (9.4\%) for nitrites and 27 (3.9\%) for glycosuria.

\footnotetext{
* Correspondence: sean.currin@wits.ac.za

June Fabian and Jaya A George acted jointly in the last authorship role. 'Department of Chemical Pathology, Faculty of Health Sciences, University of Witwatersrand, 7 York Road, Parktown, Johannesburg 2193, South Africa ${ }^{2}$ National Health Laboratory Service, Johannesburg, South Africa

Full list of author information is available at the end of the article
}

(c) The Author(s). 2021 Open Access This article is licensed under a Creative Commons Attribution 4.0 International License, which permits use, sharing, adaptation, distribution and reproduction in any medium or format, as long as you give appropriate credit to the original author(s) and the source, provide a link to the Creative Commons licence, and indicate if changes were made. The images or other third party material in this article are included in the article's Creative Commons licence, unless indicated otherwise in a credit line to the material. If material is not included in the article's Creative Commons licence and your intended use is not permitted by statutory regulation or exceeds the permitted use, you will need to obtain permission directly from the copyright holder. To view a copy of this licence, visit http://creativecommons.org/licenses/by/4.0/ The Creative Commons Public Domain Dedication waiver (http://creativecommons.org/publicdomain/zero/1.0/) applies to the data made available in this article, unless otherwise stated in a credit line to the data. 
(Continued from previous page)

Conclusion: Our study shows that POC ACR has good negative predictive value and could be used to rule out albuminuria when screening for CKD. Additionally, a high proportion of participants had other urine abnormalities detected with dipsticks which may reflect kidney disease or co-morbid untreated genitourinary pathology such as urinary tract infections or endemic schistosomiasis with important implications for CKD.

Keywords: Point of care, Urine albumin creatinine ratio, Dipstick, Chronic kidney disease

\section{Background}

Sub-Saharan Africa (SSA) has a high burden of infectious diseases (ID), mostly from HIV and tuberculosis, and an emerging burden of non-communicable diseases (NCD) $[1,2]$. Together, ID and NCD are risk factors for chronic kidney disease (CKD), which has a prevalence of $10.7 \%$ in SSA [3]. The prevalence of $\mathrm{CKD}$ is predicted to rise disproportionately in low- and middle-income countries (LMIC) [4]. Therefore, early detection of CKD and appropriate management of risk factors for progression is an essential public health priority.

Persistent albuminuria is one criterion for the diagnosis of $\mathrm{CKD}$, and an independent risk factor for adverse kidney and cardiovascular outcomes [5-9]. Albuminuria, measured on more than one occasion, as a spot urine albumin to creatinine ratio (ACR), is now included as one of the diagnostic criteria for CKD [10]. Screening for albuminuria is recommended in certain highrisk groups such as those with diabetes mellitus, however results should be confirmed by a central laboratory $[11,12]$.

The lack of access to central laboratory services in LMICs is a major hurdle obstructing widespread implementation of CKD screening programs. While limited laboratory access is acknowledged in the 2012 KDIGO guidelines, there are no recommendations for using point of care (POC) devices in resource-limited settings (RLS) [10]. POC testing provides actionable results in real-time for clinical decision-making [13]. In South Africa (SA), the efficacy of POC testing is well established for diagnosing and managing patients with HIV and tuberculosis [14]. Using the existing framework established for POC testing with ID, we propose that POC testing for screening and early detection of CKD is feasible in our setting. Previous studies [15-22] have shown good negative predictive values with fair sensitivity for semi-quantitative ACR POC testing, which suggests utility as a screening test for CKD. Additionally, the ability of urine dipsticks to detect other disease markers besides albuminuria offers added benefit.

The aim of our study was to evaluate the diagnostic accuracy of a POC semi-quantitative ACR system in a RLS in rural SA, and evaluate additional urinary abnormalities discovered on dipstick analysis.

\section{Methods}

\section{Study design}

Our sub-study comprised part of the prospective African Research on Kidney (ARK) study, the methods of which have been published [23]. To summarise, the ARK study was conducted in the Agincourt Health and Demographic Surveillance Site, Mpumalanga province, SA. There were two phases of the ARK study; the first phase (November 2017 - October 2018) screened a population-based sample of 2020 rural Africans for kidney disease and associated risk factors, those between the ages of 20 and 80 were considered eligible; the second phase (November 2018 - July 2019) comprised a subsample of the first phase, stratified by CKD stage. (Fig. 1).

In phase one of the ARK study, a CKD-risk questionnaire was administered, blood pressure (BP) was measured (as per the Joint National Committee on Prevention, Detection, Evaluation, and Treatment of High Blood Pressure guidelines [24]), and voluntary counselling and HIV testing was offered to all participants according to the SA Department of Health Guidelines [25]. In the field, POC tests were performed including urine dipstick analysis using Roche

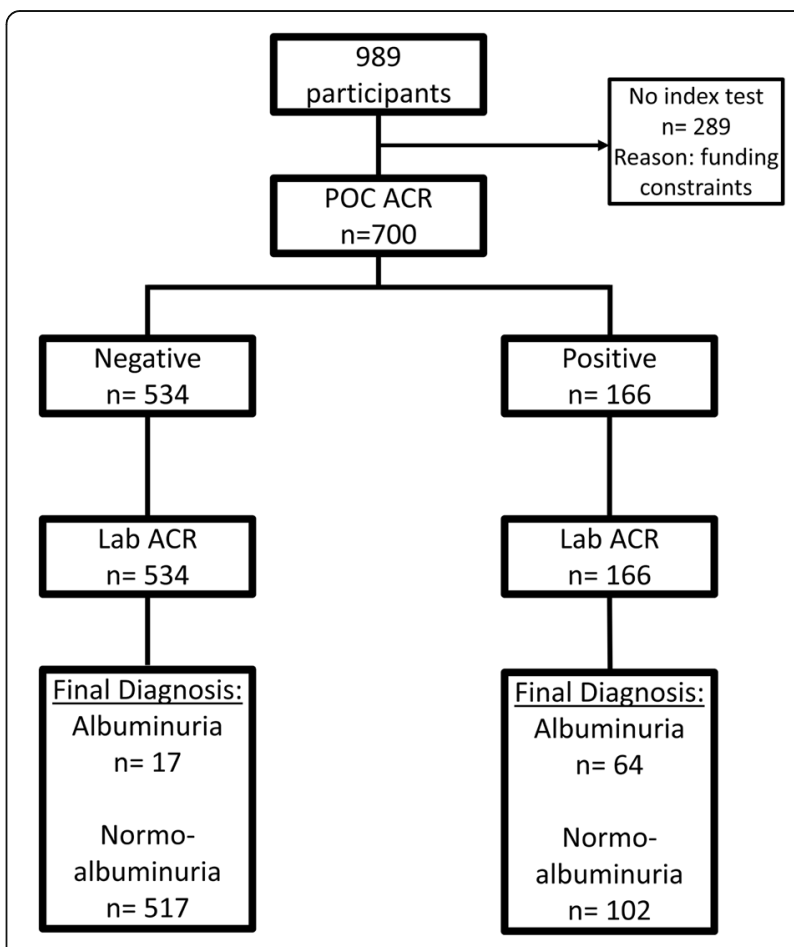

Fig. 1 Flow of participants through the study. POC ACR is the index method while Lab ACR is the reference method 
(Mannheim, Germany) Combur $10^{\circ}$ test strips on fresh spot urine samples.

The second phase of the ARK study recruited 989 participants and included the same BP and HIV testing protocols as the first phase. Spot urine samples were refrigerated overnight $\left(2-8{ }^{\circ} \mathrm{C}\right)$ and processed the following morning for storage at $-80^{\circ} \mathrm{C}$. Urine samples were transported at $-80^{\circ} \mathrm{C}$ from the study site to a central laboratory where they were processed over a nineday period. Each day, 81 samples were separated into two aliquots, one aliquot was tested using central laboratory ACR, the other aliquot was tested using a POC semi-quantitative dipstick method. Central laboratory ACR results were not known while POC ACR was performed and vice versa. 700 urine samples out of the 989 where selected based on the order in which they were sent to the central laboratory, all 700 samples were processed. Funding constraints limited the sample size to 700 out of 989 .

\section{POC ACR and dipstick analysis}

Urine dipstick analysis was performed using Sysmex Corporation (Kobe, Japan) $12 \mathrm{~S}^{\circ}$ urine dipsticks together with the Sysmex UC-1000 semi-automated urine chemistry analyser. The $12 \mathrm{~S}$ dipsticks measure the following parameters: urobilinogen, red blood cells, haemoglobin, protein, glucose, ketones, bilirubin, nitrites, specific gravity, leukocytes, $\mathrm{pH}$, creatinine, and albumin with colorimetric dipstick assays. The Sysmex UC- $1000^{\circ}$ system optically reads reaction results from $12 \mathrm{~S}$ dipsticks using multi-wavelength reflectance photometry thereby providing semi-quantitative results. The semi-automated reading of strips eliminates inter-individual variation in interpreting dipstick results. The albumin concentration is measured as $10,30,80$, or $150 \mathrm{mg} / \mathrm{L}$ using the protein error of $\mathrm{pH}$ indicator method, while the creatinine concentration is measured as $10,50,100,200$, or $300 \mathrm{mg} / \mathrm{dL}$ using the Benedict-Behre method; thereafter the ACR is calculated as dilute (albumin $10 \mathrm{mg} / \mathrm{L}$ and creatinine 10 $\mathrm{mg} / \mathrm{dL})$, normal $(<30 \mathrm{mg} / \mathrm{g}), 1+(30-300 \mathrm{mg} / \mathrm{g})$, or $2+(>$ $300 \mathrm{mg} / \mathrm{g}$ ). Internal quality control was performed each day before any samples were run.

\section{Measurement of laboratory ACR}

Laboratory albumin and creatinine measurements were performed on the Cobas c502 module (Roche Diagnostics, Mannheim), with urine albumin ( $\mathrm{mg} / \mathrm{L})$ determined using an immunoturbidimetric assay while urine creatinine $(\mathrm{mg} / \mathrm{dL})$ was determined using the kinetic Jaffe method. This was considered an appropriate reference method due to widespread usage in central laboratories in South Africa. During the nine days of measurements a single lot was used for both urine albumin and creatinine assays, internal quality control was performed twice daily as per standard practices within the central laboratory, together with an external quality assurance program.

\section{Statistical analysis}

Laboratory measurement of ACR was used as the reference method to which POC ACR was compared. Laboratory ACR was considered positive if $\geq 30 \mathrm{mg} / \mathrm{g}$ and negative if $<30 \mathrm{mg} / \mathrm{g}$. POC ACR was considered positive if falling in the " $1+$ " or " $2+$ " $(\geq 30 \mathrm{mg} / \mathrm{g})$ groups whilst negative if falling in the normal group $(<30 \mathrm{mg} / \mathrm{g})$. Samples in which the laboratory albumin was $<3 \mathrm{mg} / \mathrm{L}$ (limit of quantification) were considered as negative, as were POC ACR samples which were dilute (albumin $<10 \mathrm{mg}$ / $\mathrm{L}$ and creatinine $<10 \mathrm{mg} / \mathrm{dL}$ ). All 700 samples were included for analysis.

Statistical analysis was performed using Tibco Statistica $13^{\circ}$ and MedCalc 19.1.3 ${ }^{\circ}$. Continuous data were compared using the students T-test and Mann-Whitney test when appropriate, while categorical data were compared using $X^{2}$ test. The prevalence of albuminuria, sensitivity, specificity, positive (PPV) and negative predictive values (NPV), and likelihood ratios of POC testing were calculated using cross-tabulation. 95\% confidence intervals were calculated according to the exact ClopperPearson method for sensitivity and specificity, according to the Miettinen-Nurminen method for likelihood ratios and according to the Mercaldo-Wald method for predictive values. A $p$-value $<0.05$ was considered statistically significant.

\section{Results}

\section{Study population}

We analysed 700 urine samples; participant demographics and clinical characteristics are listed in Table 1. Mean systolic and diastolic BP were significantly higher amongst those with laboratory albuminuria, as was a history of diabetes mellitus; however, a history of hypertension was not. The prevalence of albuminuria was $11.6 \%$ (95\%CI; 9.3-14.2), based on the central laboratory ACR measurements $(\geq 30 \mathrm{mg} / \mathrm{g})$.

\section{Clinical performance of the POC ACR}

The central laboratory method identified 81 participants as having albuminuria ( $\geq 30 \mathrm{mg} / \mathrm{g}$ ) whilst the POC method, performed on the same day, identified 166 participants with albuminuria. No adverse events were reported during testing or collection. In total the POC reader misclassified 119 samples (17\%) with 102 false positives, and 17 false negatives. Sensitivity of the POC ACR to detect albuminuria (ACR $\geq 30 \mathrm{mg} / \mathrm{g}$ ) was 0.790 (95\%CI; 0.689-0.865), and specificity was 0.835 (95\%CI; 0.804-0.862). A positive likelihood ratio of 4.80 (95\%CI; $3.86-5.89)$ and negative likelihood ratio of 0.25 (95\% CI; 
Table 1 Demographic and clinical features

\begin{tabular}{lllll}
\hline & \multicolumn{2}{l}{ Laboratory ACR $(\mathbf{m g} / \mathbf{g})$} & \multirow{2}{*}{$\mathbf{p}^{\mathbf{c}}$} \\
\cline { 2 - 4 } & $<\mathbf{3 0}$ & $\mathbf{3 0}$ & $\mathbf{3 0 0}$ & \\
\hline Number of patients & 619 & 81 & 9 & \\
Age (years) & $45(25)^{\mathrm{a}}$ & $43(23)^{\mathrm{a}}$ & $55(25)^{\mathrm{a}}$ & $0.680^{\mathrm{d}}$ \\
BMI (kg/m²) & $28.1(6.2)$ & $27.3(6.5)$ & $27.0(7.0)^{\mathrm{a}}$ & $0.239^{\mathrm{e}}$ \\
Systolic BP (mmHg) & $128(14.9)$ & $133(18.1)$ & $144(24.0)^{\mathrm{a}}$ & $0.002^{\mathrm{e}}$ \\
Diastolic BP (mmHg) & $79(8.6)$ & $82(9.9)$ & $83(7.0)^{\mathrm{a}}$ & $0.019^{\mathrm{e}}$ \\
Male (\%) & $211(34.1)$ & $31(38.3)$ & $4(44.4)$ & $0.457^{\mathrm{f}}$ \\
Hypertension (\%) & $154(26.0)$ & $25(33.8)$ & $3(37.5)$ & $0.153^{\mathrm{f}}$ \\
Diabetes Mellitus (\%) $^{\mathrm{b}}$ & $29(4.9)$ & $13(17.6)$ & $2(25.0)$ & $<0.001^{\mathrm{f}}$ \\
Smoker (\%) & $85(14.3)$ & $11(14.9)$ & $0(0)$ & $0.902^{\mathrm{f}}$ \\
HIV reactive (\%) $^{\mathrm{b}}$ & $119(20.1)$ & $20(27.0)$ & $1(12.5)$ & $0.246^{\mathrm{f}}$
\end{tabular}

Data presented as mean (SD) or $\mathrm{n}(\%)$ unless otherwise indicated

a Data presented as median (IQR)

${ }^{\mathrm{b}}$ Missing values for all patients $=33$

${ }^{c}$ Comparison between laboratory negative $(<30 \mathrm{mg} / \mathrm{g})$ and laboratory positive $(\geq 30 \mathrm{mg} / \mathrm{g}$ ) groups

dMann-Whitney test

eStudents T-test

${ }^{\mathrm{f}} \mathrm{X}^{2}$ test

Hypertension, diabetes mellitus, smoker status obtained from

medical questionnaire

HIV status obtained from medical questionnaire. If previously tested, participants were asked their status; those who did not know their status, or previously tested negative, were offered voluntary counselling and testing during the home screening (see methods)

Measured blood pressure (BP): see methods

0.16-0.37) was obtained for POC ACR. Predictive values of 0.968 (95\%CI; 0.952-0.979) for negative results and 0.386 (95\%CI; 0.337-0.436) for positive results were obtained. Sensitivity and specificity to predict ACR > 300 $\mathrm{mg} / \mathrm{g}$ was 1.00 (95\%CI;0.664-1.00) and 0.987 (95\%CI; $0.975-0.994)$ respectively; with predictive values of 1.00 (95\%CI; 0.995-1.00) for negative results and 0.50 (95\%CI;0.343-0.657) for positive results.

The sensitivity and specificity of the POC ACR system varied among different groups of participants. There was reduced sensitivity (76\%) in those with a history of hypertension (medical questionnaire), however those with raised blood pressure [26] showed an improved sensitivity and specificity of 80 and $86 \%$ respectively. The same is true of those with a history of diabetes mellitus, with an improved sensitivity of $85 \%$, however, specificity was lower (66\%) in this group. Smokers, those with HIV, and those 65 years or older showed improved sensitivity. PPV remained low in all groups ranging from 0.26 to 0.52 , while NPV was high ranging from 0.90 to 0.99. (Table 2).

False negative values ranged from $30.9-57.5 \mathrm{mg} / \mathrm{g}$, and those for false positives ranged from $1.8-29.2 \mathrm{mg} / \mathrm{g}$. All nine samples with laboratory ACR $>300 \mathrm{mg} / \mathrm{g}$ were correctly identified as " $2+$ " (> $300 \mathrm{mg} / \mathrm{g}$ ) according to POC ACR, a further nine samples were classified as $>300 \mathrm{mg} /$ $\mathrm{g}$ while laboratory ACR classified them as albuminuria
(> $30 \mathrm{mg} / \mathrm{g}$ ) but less than $300 \mathrm{mg} / \mathrm{g}$. POC ACR correctly classified $572(82 \%, 95 \% \mathrm{CI} ; 79-85)$ of the samples into the correct KDIGO albuminuria stages of A1 (<30 mg/g), A2 (30 - $300 \mathrm{mg} / \mathrm{g})$ and A3 (> $300 \mathrm{mg} / \mathrm{g})$. Accuracy was 97\% (95\%CI;95-98), 31\% (95\%CI;24-39), and 50\% (95\%CI;26-74) in groups A1, A2 and A3 according to POC ACR. (Fig. 2).

\section{Additional urine dipstick abnormalities}

$240(34.3 \%)$ of the 700 samples had abnormal findings other than ACR, protein to creatinine ratio, $\mathrm{pH}$, or specific gravity. $65 \%$ (53/81) of laboratory confirmed albuminuria samples had additional abnormalities on urine dipstick. While 30\% (187/619) of the samples without laboratory confirmed albuminuria demonstrated additional urinary dipstick abnormalities. Using the dipstick method 88 (12.6\%) participants had haematuria including 50 in the laboratory negative group, and 113 (16.1\%) had leukocyturia.

Urine dipstick findings were compared between those with laboratory positive and negative ACR. Haematuria and glycosuria were significantly higher in the laboratory positive compared to the laboratory negative group ( $46.9 \%$ vs $8.1 \%$ and $11.1 \%$ vs $2.9 \%$ respectively). All abnormalities were seen with a higher proportion in those with laboratory positive ACR except for leucocytes, although not statistically significant. (Table 3).

\section{Effect of freezing on semi-quantitative POC dipstick parameters}

Freezing had a minimal effect on dipstick parameters with a small increase in false negatives and no increase in false positives being seen for haematuria and leukocyturia. (See Supplementary for detailed results and methodology).

\section{Discussion}

Our study represents the largest evaluation of a POC ACR compared to laboratory ACR to date. Similar to previous studies [15-22] we found that the POC analyser has good rule out utility for albuminuria, as indicated by the NPV. Our study differs from previous studies in that we simultaneously evaluated additional urine dipstick parameters aside from albuminuria. Similar studies [15-21] have looked at semi-quantitative POC ACR from different manufacturers, however this is the first published study on the Sysmex UC-1000 instrument. The fully automated Sysmex UC- $3500^{\circ}$ has previously been validated showing excellent precision and good analytical accuracy [22].

When using ACR to screen for albuminuria, the recommended sample is an early morning urine sample. Previous studies have used random urine $[15,18,20]$ or early morning samples $[16,17,19,21]$ with sensitivity of 
Table 2 Classification of albuminuria as positive or negative by POC and laboratory ACR

\begin{tabular}{|c|c|c|c|c|}
\hline \multicolumn{3}{|l|}{ All patients $(700)$} & \multirow{2}{*}{$\begin{array}{l}\text { Sensitivity } \\
\text { Specificity }\end{array}$} & \multirow{2}{*}{$\begin{array}{l}\mathbf{0 , 7 9} \\
0,84\end{array}$} \\
\hline & Positive POC $(n=166)$ & Negative POC $(n=534)$ & & \\
\hline Positive lab ACR $(n=81)$ & 64 & 17 & PPV & 0,39 \\
\hline Negative lab ACR $(n=619)$ & 102 & 517 & NPV & 0,97 \\
\hline \multirow[t]{2}{*}{ Hypertension (179) } & & & Sensitivity & 0,76 \\
\hline & Positive POC $(n=47)$ & Negative POC $(n=132)$ & Specificity & 0,82 \\
\hline Positive lab ACR $(n=25)$ & 19 & 6 & PPV & 0,40 \\
\hline Negative lab ACR $(n=154)$ & 28 & 126 & NPV & 0,95 \\
\hline \multirow[t]{2}{*}{ DM (42) } & & & Sensitivity & 0,85 \\
\hline & Positive POC $(n=21)$ & Negative POC $(n=21)$ & Specificity & 0,66 \\
\hline Positive lab ACR $(n=13)$ & 11 & 2 & PPV & 0,52 \\
\hline Negative lab ACR $(n=29)$ & 10 & 19 & NPV & 0,90 \\
\hline \multirow[t]{2}{*}{ Smoker (96) } & & & Sensitivity & 0,82 \\
\hline & Positive POC $(n=26)$ & Negative POC $(n=70)$ & Specificity & 0,80 \\
\hline Positive lab ACR $(n=11)$ & 9 & 2 & PPV & 0,35 \\
\hline Negative lab ACR $(n=85)$ & 17 & 68 & NPV & 0,97 \\
\hline \multirow[t]{2}{*}{ HIV (139) } & & & Sensitivity & 0,85 \\
\hline & Positive POC $(n=41)$ & Negative POC $(n=98)$ & Specificity & 0,80 \\
\hline Positive lab ACR $(n=20)$ & 17 & 3 & PPV & 0,41 \\
\hline Negative lab ACR $(n=119)$ & 24 & 95 & NPV & 0,97 \\
\hline \multicolumn{3}{|c|}{ BP: Diastolic $\geq 80$ OR Systolic $\geq 130$} & Sensitivity & 0,80 \\
\hline & Positive POC $(n=93)$ & Negative POC $(n=296)$ & Specificity & 0,86 \\
\hline Positive lab ACR $(n=56)$ & 45 & 11 & PPV & 0,48 \\
\hline Negative lab ACR $(n=333)$ & 48 & 285 & NPV & 0,96 \\
\hline \multirow[t]{2}{*}{ Age $\geq 65(105)$} & & & Sensitivity & 0,89 \\
\hline & Positive POC $(n=31)$ & Negative POC $(n=74)$ & Specificity & 0,76 \\
\hline Positive lab ACR $(n=9)$ & 8 & 1 & PPV & 0,26 \\
\hline Negative lab ACR $(n=96)$ & 23 & 73 & NPV & 0,99 \\
\hline
\end{tabular}

Hypertension, diabetes mellitus (DM), smoker status obtained from medical questionnaire

HIV status obtained from medical questionnaire. If previously tested, participants were asked their status; those who did not know their status, or previously tested negative, were offered voluntary counselling and testing during the home screening (see methods)

Measured blood pressure (BP): see methods

PPV: positive predictive value

NPV: negative predictive value

random urine samples being 0.83 [15], 0.79 [18], and 0.63 [20] while the sensitivity of early morning samples was 0.90 [16], 0.90 [17], 0.75 [19], 0.92 [21] and 0.80 [21], suggesting a possible advantage of early morning sampling [27].

Our findings show the POC device would be useful for excluding albuminuria, but any positive result would need to be confirmed with a laboratory ACR. This in keeping with other studies where NPV ranged from $0.89-0.99[15,16,18,19,21,22]$ with one study reporting a NPV of 0.71 [17]; while positive predictive value was low for all studies ranging from $0.46-0.82$ [15-19, $21,22]$. Similarly, only one study [16] reported a positive likelihood ratio above 10 indicating utility in ruling in disease.
The improved sensitivity seen in participant groups with known risk factors for CKD could help guide screening strategies. The discordance in sensitivities between a history of hypertension (medical questionnaire) and raised BP during examination could point to the effect of antihypertensives, particularly angiotensinconverting enzyme inhibitors, on albuminuria [28]. Screening strategies targeted at those with a history of diabetes mellitus, the elderly, those who present with elevated blood pressure, and those with HIV are justified, and in keeping with management guidelines [29, 30]. Our findings corroborate those of previous studies: in the study by Graziani et al. [16] the sensitivity and NPV of POC ACR improved marginally from 0.90 to 0.91 and 0.90 to 0.98 respectively in the general population versus 


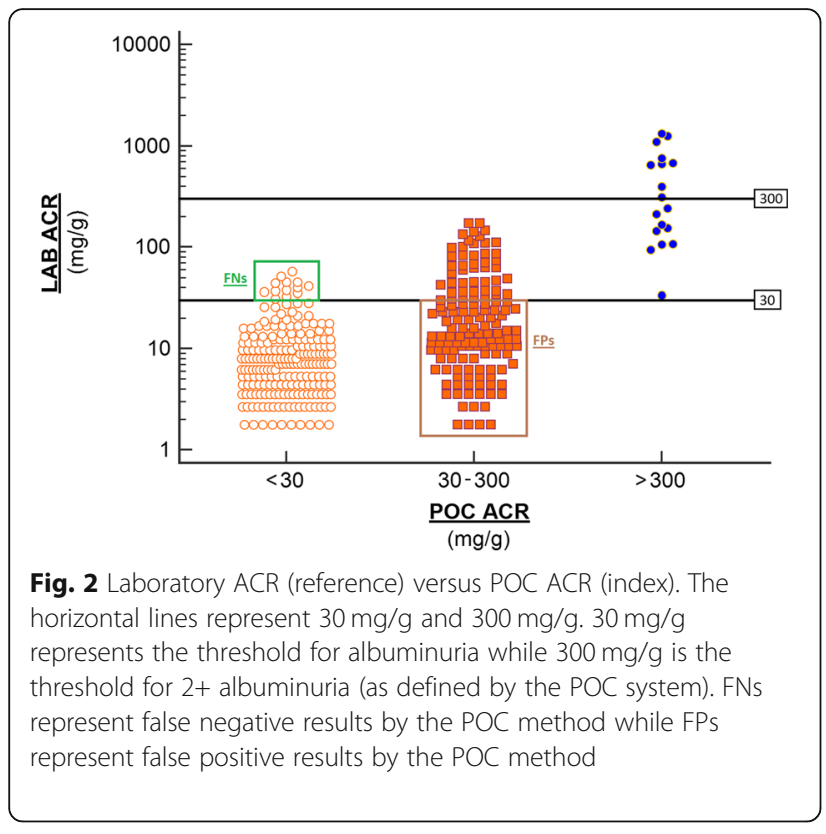

a cohort with a history of type 2 diabetes mellitus. McTaggart et al. [15] found improved sensitivity and NPV: 0.83 to 0.91 and 0.95 to 0.98 respectively in the general population compared to participants with hypertension. The study by Nah et al. [21] was conducted in prediabetic and diabetic populations with sensitivity of 0.92 and 0.80 , and NPV of 0.99 and 0.91 respectively. Our sensitivity of 0.79 and NPV of 0.97 are in keeping with random urine samples in the general population. Although the loss of specificity (increased false positives) seen in those with diabetes mellitus in our study suggests the need for confirmatory laboratory testing, the increased sensitivity in this group of participants is valuable in detecting diabetic nephropathy. Although increased sensitivity was seen in subgroup analysis, the low PPV and high NPV remained in all sub-populations suggesting that laboratory confirmation of positive results is required while negative results exclude disease.

When using POC ACR, $82 \%$ of samples were correctly classified into the correct KDIGO albuminuria stages, however, the poor performance in those with albuminuria according to POC ACR suggests category shifting in this group. Despite POC ACR having 100\% sensitivity in those with significant albuminuria $(>300 \mathrm{mg} / \mathrm{g}$ or stage A3), $50 \%$ of positive samples were false positive results. The high number of false positives and relatively few false negatives suggests that POC ACR tends to shift patients into higher concentrations of albuminuria, thus higher ACR categories. As such, negative results carry more significance, further emphasized by the $97 \%$ accuracy seen in those with POC ACR $<30 \mathrm{mg} / \mathrm{g}$.

Surprisingly, our study showed a high prevalence of abnormal urine findings besides ACR- highlighting the extent of abnormalities which can be picked up with dipstick analysis in our population. Similar findings were demonstrated during phase one of the ARK study (haematuria: $32.6 \%$ and leukocyturia: $30.3 \%$ ), while the effects of freezing at $-80^{\circ} \mathrm{C}$ were shown to have minimal effects (Supplementary). Our aims were not to validate these findings but rather to expose the extent of abnormalities seen. The epidemiology of CKD in LMICs is complex and often comprises the influence of multiple factors including NCDs, IDs, host and environmental factors [31]. Our findings suggest that strategies to decrease the impact of CKD should involve screening, diagnosing and managing $\mathrm{CKD}$, but also screening for, and managing other risk factors [32].

We found a high prevalence of haematuria on dipstick analysis. Potential explanations for isolated haematuria could be endemic urogenital schistosmiasis, a known cause of CKD in LMICs [31], or glomerular pathology that could include infectious (or other) glomerulonephritides, urogenital tuberculosis, and interstitial

Table 3 Other dipstick findings besides ACR in phase 1 and phase 2

\begin{tabular}{|c|c|c|c|c|c|c|}
\hline & Blood $^{e}$ & Urobilinogen & Bilirubin & Glucose & Leucocytes & Nitrites \\
\hline \multicolumn{7}{|c|}{ Phase $2(n=700)\left(\right.$ Sysmex $12 S^{\circledast}$ strips $^{a}$} \\
\hline Lab ACR $\geq 30$ ( $n$ and \%) & $38(46.9)$ & $1(1.2)$ & $2(2.5)$ & $9(11.1)$ & $12(14.8)$ & $12(14.8)$ \\
\hline Lab ACR < 30 ( $n$ and \%) & $50(8.1)$ & $2(0.3)$ & $4(0.6)$ & $18(2.9)$ & $101(16.3)$ & $54(8.7)$ \\
\hline TOTAL (\%) & $88(12.6)$ & $3(0.4)$ & $6(0.9)$ & $27(3.9)$ & $113(16.1)$ & $66(9.4)$ \\
\hline$p^{d}$ & $<0.001$ & 0.238 & 0.094 & $<0.001$ & 0.730 & 0.078 \\
\hline \multicolumn{7}{|c|}{ 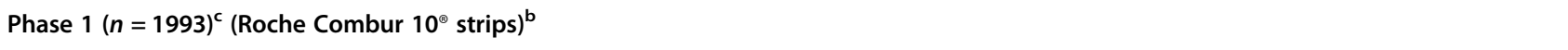 } \\
\hline TOTAL (\%) & 649 (32.6) & $36(1.8)$ & $46(2.3)$ & $64(3.2)$ & $603(30.3)$ & $49(2.5)$ \\
\hline
\end{tabular}

All data $\mathrm{n}(\%)$

${ }^{\text {a }}$ Performed on urine after a freeze thaw cycle, semi-quantitative analysis performed with Sysmex UC- $1000^{\oplus}$ device (see methods)

${ }^{\mathrm{b}}$ Performed on fresh urine during phase one, semi-quantitative analysis performed with visual inspection (see methods)

${ }^{c}$ Missing data for 27 (2 refused, 25 missing data)

${ }^{d} X^{2}$ test Lab ACR $\geq 30$ vs Lab ACR $<30$ (all phase 2 )

e Haemoglobin or erythrocytes detected by dipstick method 
nephritis. The high level of haematuria observed in the population is concerning: haematuria is associated with an increased risk of progression to ESRD [33], and plays a pathological role in renal tubular damage [34]. These dipstick findings need to be validated in our population, however previous studies have recommended dipstick analysis when screening for haematuria due to high sensitivity and reduced costs [35-38].

All the dipstick parameters except for leucocytes occurred with higher frequency in those with laboratory albuminuria; of these haematuria and glycosuria had statistical significance. This is in keeping with the role haematuria plays in various renal pathologies as well as the risk for kidney disease which is inferred from diabetes mellitus (a possible cause for glycosuria amongst others). Although not statistically significant the relatively higher prevalence of leucocytes in urine of those with laboratory negative findings was an unexpected finding. Previous studies [39-42] including a study performed on South African participants with CKD [43] showed that the presence of JC viruria was protective of developing CKD, with 43-fold higher odds of developing kidney disease in those without JC viruria. Whether these protective virurias stimulate leucocyte shedding in the urine of individuals is yet to be studied but could be a possible explanation for the raised leucocytes seen in laboratory negative individuals.

The limitations of dipstick screening such as false positives, interferences from various drugs, a lack a specificity and the need for confirmatory laboratory or microscopy testing are well known [44]. In RLS where access to central laboratory services is often limited the goals and uses of POC testing are very different to resource replete settings. Better patient outcomes with POC testing can be achieved even with decreased performance compared to laboratory-based testing if POC testing ensures improved linkage to care and retention in treatment [45]. The ability of dipstick testing to detect the potential presence of multiple risk factors for CKD and other co-morbid conditions such as diabetes mellitus, schistosomiasis, urinary tract infections, urological abnormalities, liver disease, and numerous others; together with conventional (albuminuria) and nonconventional (haematuria) markers of CKD in a single test is beneficial. Semi-quantitative (and semiautomated) results are preferable over subjective visual dipstick inspection, such semi-quantitative results aid primary care nurses who are often responsible for following screening guidelines in RLS.

Our study had several limitations: the POC testing was performed in a laboratory environment on the same day as laboratory measurements and not at the patient side, in a less controlled environment it is possible the POC instrument will not perform to the same standards. The urine samples were kept in a fridge overnight and then frozen the next day at $-80^{\circ} \mathrm{C}$ before being shipped frozen to the central laboratory. Previous studies have shown good stability of urine albumin and ACR with long term storage at $-70^{\circ} \mathrm{C}[46,47]$, urine albumin and ACR is stable for up to 7 days when stored at $4{ }^{\circ} \mathrm{C}[48,49]$. To our knowledge no studies exist on the stability of urine dipstick analysis in previously frozen samples. Dipstick analysis on samples post refrigeration up to $48 \mathrm{~h}$ has shown: glucose to be stable up to $48 \mathrm{~h}$ at $4{ }^{\circ} \mathrm{C}$; nitrites stable up to $24 \mathrm{~h}$ at $4{ }^{\circ} \mathrm{C}$; leucocytes, haemoglobin, red blood cells, bilirubin show increased false negative results at $4{ }^{\circ} \mathrm{C}$ from between 4 and 8 $\mathrm{h}[50,51]$. It is possible the POC device would perform better on fresh urine as this is the recommended sample from the manufacturer (due to bilirubin and urobilinogen deterioration), however frozen and refrigerated samples can be used if returned to room temperature [52]. Despite the widespread use of immunoassays and the kinetic Jaffe method to measure laboratory ACR, these methods remain far from ideal gold standards with which to compare POC ACR. There is currently no reference method or material for urine albumin; as such methods are not standardised despite this being a goal of the National Kidney Disease Education Program [53, 54]. Comparison of results between different methods have generally not found large biases $[53,55]$. Although isotope dilution mass spectrometry-traceability has been established for the Jaffe method and a primary reference material exists the lack of matrix-specific secondary reference materials for urine creatinine mean that calibration is not ideal [53]. Consequently, the use of laboratory ACR as the gold standard in our study was a pragmatic rather than ideal choice. Our study also has several advantages, the large sample size from a rural population in South Africa represents an important demographic group where POC testing may be most beneficial. While random urine sampling is not the recommended sample type (versus concentrated early morning sampling) it represents the situation that will be encountered across rural clinics in South Africa. We were able to process all 700 samples, without having to exclude outliers- and so better represent the clinical situation which would be encountered by health care workers.

\section{Conclusions}

We have demonstrated the good rule out utility of a POC ACR dipstick device, which could aid in excluding at risk patients who do not require confirmatory central laboratory testing in RLS. We have also shown the large number of other abnormal findings seen with urine dipstick testing in our population- which could have implications for establishing screening guidelines for multiple diseases or risks for CKD with a single test. Our study population and findings are relevant in rural Africa with limited access to central laboratory services. 


\section{Abbreviations}

CKD: Chronic kidney disease; POC: Point-of-care; ACR: Albumin-creatinine ratio; PPV: Positive predictive value; NPV: Negative predictive value; SSA: SubSaharan Africa; ID: Infectious diseases; NCD: Non-communicable diseases: LMIC: Low- and middle-income countries; RLS: Resource-limited settings; SA: South Africa; ARK: African Research on Kidney; BP: Blood pressure

\section{Supplementary Information}

The online version contains supplementary material available at https://doi. org/10.1186/s12882-021-02290-5.

Additional file 1. Table S1: Classification of haematuria and leukocyturia pre and post freezing compared to laboratory.

Additional file 2. Phase 1: FW questionnaire CKD risk - family.

Additional file 3. Phase 1: FW questionnaire CKD Risk - participant a.

Additional file 4. Phase 1: FW questionnaire CKD Risk - participant $b$.

\section{Acknowledgments}

We thank Sysmex Corporation for supplying the UC-1000 system, 125 dipsticks and quality control material for measurement of urine dipstick and albumin to creatinine ratio.

\section{Authors' contributions}

SC wrote the manuscript and performed analysis and interpretation of data while participating in elements of conception and design. The manuscript forms part of the requirements for the fulfilment of a MMed degree for SC. JG and JF acted as supervisors for the project- providing conception and design as well as guidance with data interpretation. Both supervisors actively revised the manuscript with important contributions and gave their final approval for the submitted manuscript. ST participated in conceptualising the study and editing the final draft of the paper. MG acted as the project manager, participating in project implementation and oversight, data collection, data checking; and reviewed the final draft of the paper. NM acted as the assistant project manager, participating in oversight of study procedures, data collection, data checking; and reviewed the final draft of the paper. SC acted as the laboratory manager, participating in oversight of laboratory procedures, quality control, specimen collection and processing, storage and shipping; and reviewed the final draft of the paper. BK acted as a medical laboratory technician, participating in quality control procedures, specimen collection and processing, storage and shipping; and reviewed the final draft of the paper. All authors read and approved the final manuscript.

\section{Funding}

Research was jointly supported by (i) the South African Medical Research Council, with funds from the South African National Department of Health, MRC UK (via the Newton Fund) and GSK R\&D; (ii) Faculty Research Committee Individual Research Grant, University of Witwatersrand; (iii) The International Society of Nephrology Clinical Research Program. Funders played no role in the design of the study; collection, analysis or interpretation of data or in writing the manuscript.

\section{Availability of data and materials}

The data underlying this article will be shared on reasonable request to the corresponding author.

\section{Declarations}

\section{Ethics and approval and consent to participate}

Study approval was obtained from the Human Research Ethics Committee (Medical) of the University of the Witwatersrand (M160937 and M190434) and trained fieldworkers obtained written, informed consent from participants in their first language.

\section{Consent for publication}

Not applicable.

\section{Competing interests}

The authors declare that they have no competing interests.

\section{Author details}

Department of Chemical Pathology, Faculty of Health Sciences, University of Witwatersrand, 7 York Road, Parktown, Johannesburg 2193, South Africa. ${ }^{2}$ National Health Laboratory Service, Johannesburg, South Africa. ${ }^{3}$ Faculty of Health Sciences, Medical Research Council/Wits University Rural Public Health and Health Transitions Research Unit (Agincourt), School of Public Health, University of Witwatersrand, Johannesburg, South Africa. ${ }^{4}$ International Network for the Demographic Evaluation of Populations and their Health (INDEPTH) Network, Accra, Ghana. ${ }^{5}$ Wits Donald Gordon Medical Centre, Faculty of Health Sciences, School of Clinical Medicine, University of Witwatersrand, Johannesburg, South Africa.

Received: 28 August 2020 Accepted: 2 March 2021 Published online: 20 March 2021

References

1. Naghavi M, Abajobir AA, Abbafati C, et al. Global, regional, and national age-sex specifc mortality for 264 causes of death, 1980-2016: a systematic analysis for the global burden of disease study 2016. Lancet. 2017; 390(10100):1151-210. https://doi.org/10.1016/S0140-6736(17)32152-9.

2. Mathers CD, Loncar D. Projections of global mortality and burden of disease from 2002 to 2030. PLoS Med. 2006;3(11):e442. https://doi.org/10.1371/ journal.pmed.0030442.

3. George JA, Brandenburg J-T, Fabian J, et al. Kidney damage and associated risk factors in rural and urban sub-Saharan Africa (AWI-gen): a crosssectional population study. Lancet Glob Heal. 2019;7(12):e1632-43. https:// doi.org/10.1016/\$2214-109X(19)30443-7.

4. Liyanage $T$, Ninomiya $T$, Jha $V$, et al. Worldwide access to treatment for endstage kidney disease: a systematic review. Lancet. 2015;385(9981):1975-82. https://doi.org/10.1016/S0140-6736(14)61601-9.

5. Klausen K, Borch-Johnsen K, Feldt-Rasmussen B, et al. Very low levels of microalbuminuria are associated with increased risk of coronary heart disease and death independently of renal function, hypertension, and diabetes. Circulation. 2004;110(1):32-5. https://doi.org/10.1161/01.CIR. 0000133312.96477 .48 .

6. Ärnlöv J, Evans JC, Meigs JB, et al. Low-grade albuminuria and incidence of cardiovascular disease events in nonhypertensive and nondiabetic individuals: the Framingham heart study. Circulation. 2005;112(7):969-75. https://doi.org/10.1161/CIRCULATIONAHA.105.538132.

7. Verhave JC, Gansevoort RT, Hillege HL, Bakker SJL, De Zeeuw D, de Jong PE. An elevated urinary albumin excretion predicts de novo development of renal function impairment in the general population. Kidney Int Suppl. 2004;92:S18-21. https://doi.org/10.1111/j.1523-1755.2004.09205.x.

8. Gerstein HC, Mann JFE, Yi Q, et al. Albuminuria and risk of cardiovascular events, death, and heart failure in diabetic and nondiabetic individuals. J Am Med Assoc. 2001;286(4):421-6. https://doi.org/10.1001/jama.286.4.421.

9. Park HY, Schumock GT, Pickard AS, Akhras K. A structured review of the relationship between microalbuminuria and cardiovascular events in patients with diabetes mellitus and hypertension. Pharmacotherapy. 2003; 23(12):1611-6. https://doi.org/10.1592/phco.23.15.1611.31962.

10. KDIGO Working Group. Kidney Disease: Improving Global Outcomes (KDIGO). KDIGO 2012 clinical practice guideline for the evaluation and management of chronic kidney disease. Kidney Int Suppl. 2013;3(1):1-150.

11. Ninomiya T, Perkovic V, De Galan BE, et al. Albuminuria and kidney function independently predict cardiovascular and renal outcomes in diabetes. J Am Soc Nephrol. 2009;20(8):1813-21. https://doi.org/10.1681/ASN.2008121270.

12. Sacks DB, Arnold M, Bakris GL, et al. Executive summary: guidelines and recommendations for laboratory analysis in the diagnosis and management of diabetes mellitus. Clin Chem. 2011;57(6):793-8. https://doi.org/10.1373/ clinchem.2011.163634.

13. Kazmierczak SC. Point-of-care testing quality: some positives but also some negatives. Clin Chem. 2011;57(9):1219-20. https://doi.org/10.1373/clinchem.2 011.171538.

14. Cox HS, Mbhele S, Mohess N, et al. Impact of Xpert MTB/RIF for TB diagnosis in a primary care clinic with High TB and HIV prevalence in South Africa: a pragmatic randomised trial. PLoS Med. 2014;11(11):e1001760. https://doi.org/10.1371/journal.pmed.1001760.

15. McTaggart MP, Price CP, Pinnock RG, Stevens PE, Newall RG, Lamb EJ. The diagnostic accuracy of a urine albumin-creatinine ratio point-of-care test for detection of albuminuria in primary care. Am J Kidney Dis. 2012;60(5):78794. https://doi.org/10.1053/j.ajkd.2012.05.009. 
16. Graziani MS, Gambaro G, Mantovani L, et al. Diagnostic accuracy of a reagent strip for assessing urinary albumin excretion in the general population. Nephrol Dial Transplant. 2009;24(5):1490-4. https://doi.org/10.1 093/ndt/gfn639.

17. Guy M, Newall R, Borzomato J, Kalra PA, Price C. Diagnostic accuracy of the urinary albumin: creatinine ratio determined by the CLINITEK microalbumin and DCA $2000+$ for the rule-out of albuminuria in chronic kidney disease. Clin Chim Acta. 2009;399(1-2):54-8. https://doi.org/10.1016/j.cca.2008.09.006.

18. Le Floch JP, Marre M, Rodier M, Passa PH. Interest of clinitek ${ }^{\circledast}$ microalbumin in screening for microalbuminuria: results of a multicentre study in 302 diabetic patients. Diabetes Metab. 2001;27(1):36-9.

19. Croal BL, Mutch WJ, Clark BM, et al. The clinical application of a urine albumin: Creatinine ratio point-of-care device. Clin Chim Acta. 2001;307(12):15-21. https://doi.org/10.1016/50009-8981(01)00450-8.

20. Meinhardt U, Ammann RA, Flück C, Diem P, Mullis PE. Microalbuminuria in diabetes mellitus - efficacy of a new screening method in comparison with timed overnight urine collection. J Diabetes Complicat. 2003;17(5):254-7. https://doi.org/10.1016/S1056-8727(02)00180-0.

21. Nah EH, Cho S, Kim S, Cho HI. Comparison of urine albumin-to-creatinine ratio (ACR) between $A C R$ strip test and quantitative test in prediabetes and diabetes. Ann Lab Med. 2017;37(1):28-33. https://doi.org/10.3343/alm.2017.3 7.1.28.

22. Oyaert M, Delanghe JR. Semiquantitative, fully automated urine test strip analysis. J Clin Lab Anal. 2019;33(5):1-7. https://doi.org/10.1002/jcla.22870.

23. Kalyesubula R, Fabian J, Nakanga W, et al. How to estimate glomerular filtration rate in sub-Saharan Africa: design and methods of the African research into kidney diseases (ARK) study. BMC Nephrol. 2020;21(1):1-12. https://doi.org/10.1186/s12882-020-1688-0.

24. Chobanian AV, Bakris GL, Black HR, et al. The seventh report of the joint National Committee on prevention, detection, evaluation, and treatment of High blood pressure: the JNC 7 report. J Am Med Assoc. 2003;289(19):256072. https://doi.org/10.1001/jama.289.19.2560.

25. National Department of Health. National Consolidated Guidelines for the Prevention of Mother-To-Child Transmission of HIV (PMTCT) and the Management of HIV in Children, Adolescents and Adults. Dep Heal Repub South Africa. 2015:1-136.

26. Whelton PK, Carey RM, Aronow WS, et al. 2017 ACC/AHA/AAPA/ABC/ACPM/ AGS/APhA/ASH/ASPC/NMA/PCNA guideline for the prevention, detection, evaluation, and Management of High Blood Pressure in adults a report of the American College of Cardiology / American Heart Association task force on clinical P. Hypertension. 2017;71(6):e13-e115. https://doi.org/10.1161/ HYP.0000000000000065/-/DC1.The.

27. Witte EC, Heerspink HJL, De Zeeuw D, Bakker SJL, De Jong PE, Gansevoort R. First morning voids are more reliable than spot urine samples to assess microalbuminuria. J Am Soc Nephrol. 2009;20(2):436-43. https://doi.org/10.1 681/ASN.2008030292.

28. Zhang WR, Craven TE, Malhotra $\mathrm{R}$, et al. Kidney damage biomarkers and incident chronic kidney disease during blood pressure reduction: a case-control study. Ann Intern Med. 2018;169(9):610-8. https://doi.org/10.7326/M18-1037.

29. KDOQI. Clinical practice guidelines and clinical practice recommendations for diabetes and chronic kidney disease. Am J Kidney Dis. 2007:47(5 Suppl 3):S11-145. https://doi.org/10.1053/j.ajkd.2006.12.005.

30. Diana NE, Naicker S. Update on current management of chronic kidney disease in patients with HIV infection. Int J Nephrol Renovasc Dis. 2016;9: 223-34. https://doi.org/10.2147/IJNRD.S93887.

31. Stanifer JW, Muiru A, Jafar TH, Patel UD. Chronic kidney disease in low- and middle-income countries. Nephrol Dial Transplant. 2016;31(6):868-74. https://doi.org/10.1093/ndt/gfv466.

32. Jha V, Arici M, Collins AJ, et al. Understanding kidney care needs and implementation strategies in low- and middle-income countries: conclusions from a "kidney disease: improving global outcomes" (KDIGO) controversies conference. Kidney Int. 2016;90(6):1164-74. https://doi.org/10.1 016/j.kint.2016.09.009.

33. Vivante A, Afek A, Frenkel-Nir Y, et al. Persistent asymptomatic isolated microscopic hematuria in Israeli adolescents and young adults and risk for end-stage renal disease. J Am Med Assoc. 2011;306(7):729-36. https://doi. org/10.1001/jama.2011.1141.

34. Moreno JA, Sevillano Á, Gutiérrez E, et al. Glomerular hematuria: Cause or consequence of renal inflammation? Int J Mol Sci. 2019;20(9). https://doi. org/10.3390/ijms20092205.
35. Bataille A, Wetzstein M, Hertig A, Vimont S, Rondeau E, Galichon P. Evidence of dipstick superiority over urine microscopy analysis for detection of hematuria. BMC Res Notes. 2016;9(1):435. https://doi.org/10.1186/s13104-016-2240-y.

36. Anigilaje EA, Adedoyin OT. Correlation between dipstick urinalysis and urine sediment microscopy in detecting haematuria among children with sickle cell anaemia in steady state in Ilorin, Nigeria. Pan Afr Med J. 2013;15:135. https://doi.org/10.11604/pamj.2013.15.135.1854.

37. Arm JP, Peile EB, Rainford DJ, Strike PW, Tettmar RE. Significance of dipstick haematuria. 1. Correlation with microscopy of the urine. Br J Urol. 1986; 58(2):211-7. https://doi.org/10.1111/j.1464-410x.1986.tb09029.x.

38. Arm JP, Peile EB, Rainford DJ. Significance of dipstick haematuria. 2. Correlation with pathology. Br J Urol. 1986;58(2):218-23. https://doi.org/1 0.1111/j.1464-410x.1986.tb09030.x.

39. Divers J, Núñez M, High KP, et al. JC polyoma virus interacts with APOL1 in African Americans with nondiabetic nephropathy. Kidney Int. 2013:84(6): 1207-13. https://doi.org/10.1038/ki.2013.173.

40. Freedman $\mathrm{Bl}$, Kistler AL, Skewes-Cox $\mathrm{P}$, et al. JC polyoma viruria associates with protection from chronic kidney disease independently from apolipoprotein L1 genotype in African Americans. Nephrol Dial Transplant. 2018;33(11):1960-7. https://doi.org/10.1093/ndt/gfx368.

41. Pires EP, Bernardino-Vallinoto CV, Alves DM, et al. Prevalence of infection by JC and BK polyomaviruses in kidney transplant recipients and patients with chronic renal disease. Transpl Infect Dis. 2011;13(6):633-7. https//doi.org/10.1111/j.1399-3062.2011.00614x.

42. Kruzel-Davila E, Divers J, Russell GB, et al. JC viruria is associated with reduced risk of diabetic kidney disease. J Clin Endocrinol Metab. 2019;104(6): 2286-94. https://doi.org/10.1210/jc.2018-02482.

43. Nqebelele NU, Dickens C, Dix-Peek T, Duarte R, Naicker S. JC virus and APOL1 risk alleles in Black south Africans with hypertension-attributed CKD. Kidney Int Rep. 2019;4(7):939-45. https://doi.org/10.1016/j.ekir.2019.05.006.

44. Simerville JA, Maxted WC, Pahira JJ. Urinalysis: a comprehensive review. Am Fam Physician. 2005;71(6):1153-62

45. Drain PK, Hyle EP, Noubary F, et al. Diagnostic point-of-care tests in resource-limited settings. Lancet Infect Dis. 2014;14(3):239-49. https://doi. org/10.1016/\$1473-3099(13)70250-0.

46. Chapman DP, Gooding KM, McDonald TJ, Shore AC. Stability of urinary albumin and creatinine after 12 months storage at $-20^{\circ} \mathrm{C}$ and $-80^{\circ} \mathrm{C}$. Pract Lab Med. 2019;15(March):e00120. https://doi.org/10.1016/j.plabm.2019.e00120.

47. Kania K, Byrnes EA, Beilby JP, Webb SAR, Strong KJ. Urinary proteases degrade albumin: implications for measurement of albuminuria in stored samples. Ann Clin Biochem. 2010;47(Pt 2):151-7. https://doi.org/10.1258/acb.2009.009247.

48. Herrington $W$, Illingworth N, Staplin N, et al. Effect of processing delay and storage conditions on urine albumin-to-creatinine ratio. Clin J Am Soc Nephrol. 2016;11(10):1794-801. https://doi.org/10.2215/CJN.13341215.

49. Osberg I, Chase HP, Garg SK, et al. Effects of storage time and temperature on measurement of small concentrations of albumin in urine. Clin Chem. 1990;36(8 Pt 1):1428-30. https://doi.org/10.1093/clinchem/36.8.1428.

50. Froom P, Bieganiec B, Ehrenrich Z, Barak M. Stability of common analytes in urine refrigerated for $24 \mathrm{~h}$ before automated analysis by test strips. Clin Chem. 2000;46(9):1384-6.

51. Ekşioğlu MK, Madenci ÖÇ, Yücel N, et al. The effectiveness of BD vacutainer ${ }^{\oplus}$ plus urinalysis preservative tubes in preservation of urine for chemical strip analysis and particle counting. Biochem Medica. 2016;26(2):224-32. https//doi.org/10.11613/BM.2016.024.

52. Sysmex Corporation. MEDITAPE UC-12S (Package Insert).; 2017.

53. Miller WG, Bruns DE, Hortin GL, et al. Current issues in measurement and reporting of urinary albumin excretion. Clin Chem. 2009;55(1):24-38. https:// doi.org/10.1373/clinchem.2008.106567.

54. Speeckaert MM, Speeckaert R, Van De Voorde L, Delanghe JR. Immunochemically unreactive albumin in urine: fiction or reality? Crit Rev Clin Lab Sci. 2011;48(2):87-96. https://doi.org/10.3109/10408363.2011.591366.

55. Seegmiller JC, Sviridov D, Larson TS, Borland TM, Hortin GL, Lieske JC. Comparison of urinary albumin quantification by immunoturbidimetry, competitive immunoassay, and protein-cleavage liquid chromatography-tandem mass spectrometry. Clin Chem. 2009:55(11):1991-4. https:/doi.org/10.1373/dinchem.2009.129833.

\section{Publisher's Note}

Springer Nature remains neutral with regard to jurisdictional claims in published maps and institutional affiliations. 